\title{
Biosecurity risk factors presented by international vessels: a
}

\section{statistical analysis}

Sandy Clarke ${ }^{1}, \leftarrow$ Tracey Hollings ${ }^{2}$, Nianjun $\mathrm{Liu}^{3}, \leftarrow \mathrm{Greg} \mathrm{Hood}^{3}$, and Andrew Robinson ${ }^{2 *}$

${ }^{1}$ Statistical Consulting Centre, University of Melbourne, Melbourne, VIC 3010, Australia

${ }^{2}$ Centre of Excellence for Biosecurity Risk Analysis, University of Melbourne, VIC 3010, Australia

${ }^{3}$ Department of Agriculture and Water Resources, Canberra, ACT, Australia

*Corresponding author: apro@unimelb.edu.au

\section{Abstract--}

Invasive non-indigenous species are among the greatest threats to global biodiversity.

Shipping is the principal vector for international dispersal of nonindigenous species, and shipping rates are increasing globally. The Australian government performs a range of regulatory actions to mitigate biosecurity risks associated with marine vessels, and in so doing has amassed a large volume of operational inspection data. This data can be used to quantitatively examine risk factors of vessels failing biosecurity procedures after arriving from international ports, the nature of biosecurity failures, and the types and seizure rates of biosecurity risk material (BRM). Classification trees with gradient boosting were used to assess characteristics that predict high risk vessels $(n=93,006)$ for carrying BRM, across seven years of inspection data. Undeclared vessels and suspected irregular entry vessels posed the highest risk, but both were rare. Vessels that visit infrequently (<20 visits in seven years) were common and had almost three times greater odds of failing inspection than vessels visiting frequently. On statistical analysis, yachts appeared to pose less risk than 
commercial vessels. In operational terms, a tentative profiled $20 \%$ fraction would contain $57 \%$ of genuine failures, and the concomitant non-screened group would contain $82 \%$ of passes. The most common reason for inspection failures was ballast water non-compliance $(2.53 \%)$ and plant or insect detections (1.77\%); biofouling was less common $(0.13 \%)$ but testing for biofouling is not exhaustive. Invertebrate species comprised almost $90 \%$ of invasive organisms detected and seized from vessels failing biosecurity inspections. This study targets an entire transportation vector, which includes many pathways. Understanding the characteristics of transport vectors is pivotal to characterising the risk of biological invasions and applying adequate controls and prevention strategies. Our results show that biosecurity risk is not uniform on maritime pathways, so there is considerable scope for biosecurity regulators to impose risk-based intervention.

\section{KEYWORDS}

Vessels, biosecurity, invasive species, shipping, marine, Australia, risk, classification trees 


\section{INTRODUCTION}

Invasive non-indigenous species are among the greatest threats to biodiversity and are now so widespread that they contribute significantly to global environmental change (Vitousek et al. 1996). A myriad of harmful non-indigenous species are unintentionally introduced as a result of global trade (Carlton et al. 1995; Hulme 2009; Levine and D'Antonio 2003) and shipping constitutes a major vector for invasion by aquatic and terrestrial organisms (Molnar et al. 2008). Human-mediated invasions are recorded within almost all regions of the world and are related to transport vectors that increase the overall rate and pool of invasive species by removing natural barriers to dispersal, such as ocean currents and distance (Paini and Yemshanov 2012; Ruiz et al. 1997). Increasing global trade, changing policies, and the expanding global economy are inadvertently contributing to biological invasions and increasing the difficulty of preventing incursions (Bax et al. 2003; Hayes 2003; Hewitt and Campbell 2007; Ruesink et al. 1995; Vitousek et al. 1996). As an example, the rapid spread of the Eurasian zebra mussel (Dreissena polymorpha and Driessena bugensis) in North America highlights the economic and biological ramifications of unintended marine invasions. The mussels' continued spread through rivers, lakes and canals is changing entire ecosystems and causing local extinctions (Ricciardi et al. 1998), and their removal from intake pipes was estimated to cost more than $\$ 3.1$ billion within a decade (Vitousek et al. 1996).

Despite increasing attention being paid to incursions of non-indigenous species, the processes and pathways by which they enter is still relatively poorly understood (Acosta et al. 2010). Newly detected incursions are often beyond the point of control, so ameliorative efforts may more profitably concentrate on preventing organisms from reaching the border (Hewitt and Campbell 2007). 
A border-focused strategy requires a greater understanding of entry pathways. The incursive success of an invasive species is determined by species characteristics, the pathways that it travels, and the suitability of the site at which it enters (Brockerhoff et al. 2006; Hayes 2003) and research has most often focused on the first and third; namely, why species have been able to establish in new environments or how susceptible an environment is to incursion (Floerl et al. 2005). This approach may be oversimplified, however, and may miss complex interactions because it concentrates on a small subset of successful invaders (Floerl and Inglis 2005). Given the uncertainty and disparity around transport frequency relative to invasion frequency (Wonham et al. 2001) it may be more valuable to consider all incursions as potentially harmful and focus on predicting high risk vectors (Floerl et al. 2005), and how humans facilitate the introduction of species into new environments (Floerl and Inglis 2005).

Shipping is the major form of transport for international commodities, carrying more than $90 \%$ of the world's trade, and experienced an almost four-fold increase in cargo transported since the 1970's (International Maritime Organisation 2012). Vessels are also cited as the single most important vector responsible for the global transfer of nonindigenous marine species (Hayes 2003; Molnar et al. 2008). This typically occurs through the release of ballast water (Seebens et al. 2013) and biofouling (Roberts and Tsamenyi 2008), but at least 19 preborder pathways are recognised on a typical vessel (Carlton et al. 1995; Hayes 2003). Several factors contribute to the risk of a vessel transporting and releasing biosecurity risk material (BRM), including the characteristics of the vessel, the port of origin, route and duration of voyage, the species biology and habitat requirements, and the suitability of the destination port - regardless of the cargo (e.g. Floerl and Inglis 2005; Hulme 2009; Minchin and Gollasch 2003; Roberts and Tsamenyi 2008; Ruiz et al. 1997; Wonham et al. 2001). Modern ships are larger, faster, increasing the number, range and frequency of ports visited, and consequently, the opportunities for invasion and the diversity of donor regions (Bax et al. 
2003; Carlton 1996; Hewitt and Campbell 2007; Hulme 2009; Minchin and Gollasch 2003; Ricciardi 2001). Specific vessel characteristics and pathways that pose the greatest biosecurity risks should be identified in order to manage the threat of incursions by nonindigenous organisms arriving on vessels (Coutts and Taylor 2004). For example, twenty years ago the ballast water pathway alone transported an estimated 10,000 species annually to new countries, though in most cases spatial and temporal barriers prevented their survival and establishment (Carlton 1996). Terrestrial nonindigenous species are also a significant concern arriving on vessels and containers. In New Zealand between 1950-2000, more than 1500 individuals from 109 bark beetle species (Subfamily: Scolytinae) were intercepted at the border, most often in dunnage. The source of these beetles could be traced to 59 different countries. Many of these species are considered significant forest pests and the number passing the border is believed to be considerably higher as only $\sim 10 \%$ of shipments were examined (Brockerhoff et al. 2006)

Australia's relative isolation and ocean border necessitate a heavy reliance on shipping for trade. More than $99 \%$ of Australia's imports and exports are transported by over 15,000 vessel transports that arrive in Australia annually from overseas ports (Bureau of Infrastructure Transport and Regional Economics (BITRE) 2015a; Bureau of Infrastructure Transport and Regional Economics (BITRE) 2015b). This makes Australia particularly susceptible to the human-mediated transfer of non-indigenous organisms, amid a wide range of vessel types including cargo and container ships, commercial fishing vessels and bulk carriers (Piola and McDonald 2012). Biodiversity impacts on Australia's unique biota and economic losses have been documented following the establishment of non-indigenous species introduced via shipping. A notorious example, the northern Pacific seastar, was introduced into the Derwent River in Tasmania with the release of ballast water from a vessel from Japan. In less than a decade the population of this large, highly mobile predator 
surpassed 30 million and had recorded the highest densities in the world (Thresher 1999). Incursions such as these are not entirely surprising given the ballast water discharge from foreign ports in Australia is more than 34 million litres an hour (Cope et al. 2015).

The Australian federal Department of Agriculture and Water Resources (DAWR) operates a complex and diverse biosecurity system to reduce the risk of pests and diseases entering Australia. The biosecurity system is important for protecting the environment, maintaining the competitiveness of the agricultural sector, and underpinning Australia's reputation as a reliable producer of quality food and fibre. DAWR is tasked with ensuring that the biosecurity risk posed by vessels arriving in Australia from overseas is adequately managed. It also acts on behalf of the Department of Health to ensure that these vessels comply with International Health Regulations. Australian authorities have the authority to inspect high risk vessels on arrival at the border, but often rely more on preventative actions by vessel operators to ensure compliance with regulations, such as those related to biofouling (Piola and McDonald 2012). Identifying high risk vessels ensures that resources are applied to areas that pose the greatest biosecurity threat and help authorities assess new vessels every year, without having access to vessel history or prior records (Keller et al. 2011; Liu and Tsai 2011). Many countries are moving towards risk based assessments to aid inspectors in targeting high risk vessels, by considering maintenance and travel history and prior compliance (Hewitt and Campbell 2007). Risk assessments cover a range of qualitative and quantitative tools and techniques that can estimate the likelihood and consequences of adverse events (Hewitt and Campbell 2007).

Biosecurity hazards are broadly defined into three groups: vectors, pathways and species, with many biosecurity risk assessments usually applied to pathways (Hayes 2003). However, issues arise where a single vector such as shipping can have multiple pathways (Hayes 2003) and where an element of stochastic uncertainty exists for specific species, for example, their 
probability of survival and transport. Therefore it is potentially of more value to target and predict high risk vectors that may contain various organisms (Floerl et al. 2005) although this has rarely been done in practise. Quantitative assessments for biosecurity applications are also relatively rare due to complex issues and/or scarcity of reliable data, but they generally provide more reliable and defensible information from which a measure of prediction error can be derived (Floerl et al. 2005; Hayes 2003). However, recently more advanced statistical techniques, such as classification trees, pathway models and network based invasion models, have been applied to biosecurity applications for shipping and with the potential to increase the effectiveness of risk screening processes (Floerl et al. 2005; Lacoursière-Roussel et al. 2012; Paini and Yemshanov 2012; Seebens et al. 2013).

DAWR has a large volume of operational data that can be used to generalise patterns of biosecurity risk across a broad range of vessels, their characteristics and movements. This paper assesses the characteristics that predict high risk vessels arriving from international ports for carrying biosecurity risk material, and develops effective predictive models to improve targeted inspection. The analysis reported herein focuses on the biosecurity risk presented by the vessels themselves as opposed to the cargo that is transported by the vessels, which undergoes different risk-mediating intervention. We also analyse the nature of biosecurity failures recorded for vessels that have failed border inspections, and the types and seizure rates of BRM arriving with vessels over the six-year period 2010-2015. If specific attributes can be identified of vessels that facilitate the movement of nonindigenous species, then authorities can use this information to determine the risks of individual vessels even where no history or prior records are available. Analysis of risk factors is an efficient way to estimate the potential of a vessel to bring BRM into Australia.

In contexts characterised by a very large number of potential predictors, traditional methods can result in over-specified models which perform poorly on data not used to construct them. 
If we want to avoid spurious relationships or to be able to generalise our model to wider contexts, we can attempt to do so with the creation of many models based on random samples of the observations and averaging the results of these models. Here we use decision trees as the elemental models. These aggregative models are called random forests as they involve many trees generated from random samples of the data. These approaches are now considered to be superior to classical methods in such contexts (Fernandez et al. 2014). In addition to avoiding overfitting, these models also enable more flexible functional forms and complex interactions. A Gradient Boosting Machine is a guided version of a random forest, that seeks to improve prediction with targeting of unsuccessful predictions in a step-wise approach. 


\section{METHODS}

\subsection{Vessel inspection data}

The DAWR vessel inspection data from $1^{\text {st }}$ July 2006 to $31^{\text {st }}$ October 2013 were available for analysis. The database contained a large source of raw operational data including information on voyages, visits and inspections, and included vessel name, vessel type, call sign and International Maritime Organisation (IMO) number, agent name, visit date and time. Most vessels are inspected at the first port of call. A vessel may also be inspected at the subsequent ports it visits during a journey in Australia, depending on policy requirements. There are up to ten types of vessel inspections that may be undertaken by a biosecurity officer to meet multiple requirements at the port, including for example routine vessel inspection (RVI), crew only, surveillance, and non-inspection. Routine inspections with a recorded result are the focus of this paper.

The possible outcomes of these routine inspections are a pass, a non-conformity or a failure. A pass means that the vessel is relieved of the on-arrival biosecurity obligations, however may continue to be subject to certain biosecurity restrictions unless fully released from biosecurity control. Most commercial vessels continue to be subject to certain biosecurity control restrictions unless (i) they have been fully released from biosecurity control by leaving Australian Territory and going overseas or (ii) have been stripped of all biosecurity risk material to an acceptable level for the vessel to be fully released from biosecurity control. A non-conformity is an intermediate outcome in which the inspector considers an outcome to be non-compliant but not disastrously so, and a failure means that some treatment or corrective action must be undertaken before the vessel can be released. The binary outcome of interest for the analysis reported in this paper is failure / non-failure. 
The dataset contained 93,006 vessel visits with routine inspections: 82,991 passes, 5,691 nonconformities and 4,324 failures. A separate file with 39,486 entries containing the names of shipping agents was also supplied, as agent was identified as a likely risk factor by seaport experts. Using inspection date, time and IMO number, matches could be obtained for 23,775 of the inspections. The remaining inspections were coded as 'unmatched' for agent name, which is a unique and potentially relevant level of this field.

All of the potential risk factors relevant for modelling in the vessel inspection database can be treated as categorical variables. Several categorical variables had many levels, including some that corresponded to very small vessel counts. For last country, current port and agent name, levels with less than 100 counts were collapsed into two groups: less $\psi$ than $\psi 20$ counts and 20-99 counts. For last port and vessel name, there was a particularly large spread of possible levels, so levels with less than 200 counts were collapsed into three groups: less than 20 counts, 20-99 counts and 100-199 counts. As well as simplifying these variables for analysis, this enables any new, rare levels to be included in future predictive modelling by assigning them to the smallest category. There were very few missing values for these data, aside from agent name due to a match failure and exclusions due to a compliance-based inspection policy, where the missing values were included as a level for the purposes of modelling. Visit length category had an existing level called 'Unknown' and vessel class had a level 'Undeclared', both included as category levels for the purposes of modelling. For analysis, all fields were converted into a series of dummy variables, one for each level (1 indicating that level was present for the given record and 0 otherwise), to reduce the data complexity and separate out the effects of individual levels more clearly. This resulted in 348 possible risk factors in total. 


\subsection{Data analysis}

An initial reduction of factors (also known as feature selection) was performed, before a complex model with all factors and their interactions could be considered. In order to do this, the dataset was randomly divided into two halves, a training set and a test set. The training set was used to fit a simple generalised linear model which was then used to predict failures for the test set. The performance of this was assessed using the area under the ROC curve (AUC) for the test set; a common means for assessing predictive performance. This process was repeated 5 times and summarised by the average AUC. Any factor that had an average AUC greater than 0.505 was carried over into the next analysis step; note that an AUC of 0.5 or less indicates no predictive power. All factors were considered independently of each other at this stage. Table 1 contains the list of all factors and levels that were carried into the next phase of analysis, 80 in total, because of evidence of individual predictive power. Note that predictive power doesn't only imply greater biosecurity risk; this also includes factors which

show notably lower risk as these can also inform predictive models. Even though the visit and inspection dates were similar, the presence of differences necessitated consideration of both. The featured years, quarters and months were similar for both inspection and visit dates (e.g. the inspection months of May and the visit date of May both feature); this is unsurprising given that these dates are identical in many cases. Vessels with small numbers of visits feature in this table, indicating that vessels which occur rarely in the data set seem to be related to risk. Agent was anticipated by experts involved to be a key predictor, with two agent names demonstrating some predictive power. Many inspections did not have a match for the agent name, which was an important predictor in its own right.

Once the set of predictors was sufficiently reduced, a model combining these factors could be used. The modelling approach used involved large numbers of classification trees with 
boosting and shrinkage, using the gradient boosting machine package (gbm) in R ( $\mathrm{R}$ Core Team 2014; Ridgeway 2013). Tree-based models progressively split observations into two groups, for which the splits are based on levels of the predictors. This approach allows for complex relationships between predictors and outcomes, including interactions between predictors in the way they affect the outcome, and it can handle a range of different predictor types as well as predictors with missing values. The boosting and shrinkage aspect involves fitting these tree models many times and, for each new step, weighting those observations that were hardest to classify correctly in the previous step. This is a reasonably computationally intense method, but can still be implemented on a standard desktop with the initial data reduction steps discussed above. The specifics of the model used here draw on the findings of Miller et al. (2009).

Although the full data were used to determine the risk factors, in order to best assess the performance of the model in terms of prediction, it was appropriate to separate the data into testing and training data. In order to do this, we used the same modelling as above for a randomly selected $80 \%$ of the data, which is then used to predict the risk for the $20 \%$ not used for the model development. This process was repeated 5 times on five distinct partitions of the data; known as 5-fold cross validation. The actual model outcome is an estimated risk of failure between 0 and 1, which gives a risk ranking for all vessel visits. The assessment of the model predictions therefore involves choosing a screening fraction (akin to the sampling rate chosen in practice) and selecting that fraction of visits as estimated by the model to be the highest risk, based on the rankings. We can then assess the percentage of visits within that sample that were true failures (the sensitivity) and the percentage of visits outside the sample that were true passes (the specificity). We want both of these percentages to be high, but there is typically a trade-off between them in practice; if we screen more we will detect more failures, but we will also spend resources screening unnecessarily. 
We also present results for the reasons for both failure and non-conformity of vessels arriving from international ports in a random sample of 1,000 vessels in 2012-2013, and the types and rates of seizures of biosecurity risk material that was detected over six years from $1^{\text {st }}$ January $2010-31^{\text {st }}$ December 2015. 


\section{RESULTS}

\section{Vessel Characteristics}

A model based on many average classification trees can be used directly for prediction, but can also provide an indication of which factors are important in predicting risk. We consider the effect of each predictor, averaged over the other factors, using overall measures of importance. Table 2 provides a list of these relative measures of importance for the top 18 factor/level combinations. These importance values are the relative contribution of each predictor to all the trees generated, calculated by comparing the predictive power of trees with this predictor, compared to those with this predictor randomly permuted to distort its relationship to the outcome. These importance values have been standardised such that the largest value is set to 100. Each row also contains an odds ratio for the relative odds of failure for vessels with that variable level compared to those without it, to give an indication of the strength of the biosecurity risk. For example, if the vessel class is 'Undeclared', the overall odds ratio is estimated to be 70.2 ; that is, the odds of failure if the vessel class is undeclared is more than 70 times higher than other vessel classes combined. The final column of Table 3 gives the rarity of the factor level as a percentage, which affects its usefulness as a predictor of risk in general. For example, while the vessel class being undeclared is a strong predictor of risk, this only occurs in $0.4 \%$ of vessels. These results do not describe the nature of any interactions between fields in the model, though undoubtedly such effects are going to be involved. Such effects are included in the model itself and any specific prediction arising from the model.

Undeclared vessels had the highest importance of any other variable by a factor of more than 3. The highest odds ratio was for suspected irregular entry vessel types with an extremely high 907.5. These types of vessels and undeclared vessels are extremely risky (and ought to 
always be screened) but these are also relatively rare occurrences in the VMS data. More common are vessels which infrequently visited Australia, those with less than 20 visits. The odds ratio indicates these vessels have 2.7 times greater odds of failure than other vessels. Several ports feature in the top 18 factor levels. The north-eastern ports had the largest number of arrivals and also higher risk; however the single port with the greatest relative importance was Port Hedland in NW Australia with $7.7 \%$ of vessel arrivals. Christmas Island represented the highest risk, having 6.3 times greater odds of failure than vessels docking at other ports.

The results for vessel name indicated that vessels which visited Australia infrequently during the seven-year timeframe of the data comprised almost two thirds of all arrivals from international ports, and had an odds of failure three times higher than those with more than 20 visits.

\section{Performance of the prediction model for test data}

Table 3 gives the results for a range of screening fractions to assess the prediction performance of the model. There is a clear trade-off between sensitivity and specificity when choosing the fraction of vessels considered high risk. If we were to screen the top $20 \%$ of vessels in terms of risk as predicted by our model, we estimate that we would find that our screened group contained $57 \%$ of the genuine failures $(2,465$ out of 4,324$)$ and our nonscreened group contains $82 \%$ of the passes $(72,719$ out of 88,682$)$. This corresponds to an odds ratio (OR) of 5.94 (95\% CI: 5.58, 6.32). As we increase the screened fraction, the sensitivity improves (we detect more failures) but at the expense of specificity (we also increase our false positives) and, in practice, increased screening resources and cost.

We can also represent this performance on a continuum, as in the receiver operating characteristic (ROC) curve in Figure 1. This clearly indicates the trade-off between 
increasing the true positive rate and keeping the false positive rate low. The dashed line depicts the results that would be expected from random sampling with no profiling. The choice of a screening fraction will depend on the cost of screening relative to the seriousness of failing to detect a genuine failure.

\section{Biosecurity failure types}

In order to get an indication of the nature of biosecurity failures, a random sample of 1000 inspections from 2012-2013 was assessed in more detail. The results of this have been given in Table 4. Document errors were commonly involved in failures, but overall ballast water $(2.53 \%)$ and plant or insect detections $(1.77 \%)$ were the most common reasons for not passing a vessel inspection (Table 4). Biofouling was one of the least common reasons for vessels failing biosecurity inspections and in all cases it was considered a failure rather than the less serious non-conformity. Biofouling however is rarely tested for, due to difficulties with in-water hull inspections, so it is expected that real failure rates would be considerably higher.

\section{Types of organisms arriving}

In order to estimate the profile of organisms arriving on vessels, the incident data of organisms detected on vessels which were classified as failures or non-conformities was analysed from $1^{\text {st }}$ January $2010-31^{\text {st }}$ December 2015 . Note that the detections of some organisms were classified as non-conformities, rather than fails, so the definition does not exactly marry with our earlier definition, but the difference is trivial for our purposes. This dataset comprised 3,980 unique vessels with records available for 7,068 incidents of organisms seized, indicating that a vessel which has classified as a fail or non-conformity for biosecurity regulations is likely to be carrying more than one organism of biosecurity concern. Invertebrate species represented a significant proportion of total organisms removed 
from vessels (87\%) (Figure 2a). Seeds were the next highest group of detections and seizures $(8 \%)$. Plants and animals had the lowest detection rates of $2 \%$. The nature of the vessel inspection procedures means the data is heavily biased towards terrestrial and non-aquatic species. Species contained in ballast water, biofouling species and aquatic organisms generally were significantly under-represented in this dataset.

Several organisms of significant biosecurity concern to Australia were detected and removed from vessels. Together these organisms accounted for almost $6 \%$ of total organisms seized from vessels during 2010-2015 and included the Giant African snail (Achatina fulica), tramp ant (Pheidole megacephala; Linepithema humile; Lepisiota frauenfeldi; Wasmannia uropunctata; Anoplolepis gracilipes; Solenopsis invicta; Solenopsis geminata), and Asian gypsy moth (Lymantria dispar) (Figure 2b). This figure is also likely to be substantially underestimated as data were used only where there were full records of species names; many records were included only to family or genus level. 


\section{DISCUSSION}

Shipping is the principal vector for transporting nonindigenous species around the world (Roberts and Tsamenyi 2008) and successful invaders are increasing concomitantly with shipping rates (Ricciardi 2001). Quantitative risk analyses can be implemented as a key component of border security, to examine risk factors of vessels failing biosecurity procedures after arriving from international ports, the reasons for their failure and the types of organisms arriving.

Rather than focus on a small suite of species and their biological and ecological tolerances of source and destination ports, this study targets an entire transportation vector, which includes many pathways and incorporates variation in vessel and operator characteristics, and omits analysis of the risks presented by the cargo (Floerl et al. 2005). Undeclared vessels and suspected irregular entry vessels were found to be the highest risk vessels, though both were extremely rare, comprising just $0.6 \%$ of all vessel arrivals combined. The most common reasons for vessels not conforming to or failing biosecurity requirements were detection of plant and insect material and ballast water issues. Adherence to ballast water regulations is critical as ballast water can transport large numbers of species, including fish, and is a significant dispersal vector of non-native marine organisms (Carlton 1996; Molnar et al. 2008; Seebens et al. 2013). This quantitative risk assessment can categorise high risk transport vectors before they reach country borders, allowing them to be targeted and successfully managed pre-border to prevent or lessen the number of unwanted introductions (Floerl et al. 2005; Paini and Yemshanov 2012; Seebens et al. 2013).

Vessels that infrequently visit Australia account for two thirds of all vessel arrivals, and have almost three times greater odds of failing biosecurity checks at the border. Authorities are being confronted with thousands of new vessels every year without having records for those 
vessels to form risk profiles. This is common for ports around the world; in one of the busiest seaports in the world, the Port of Kaohsiung, only $1.4 \%$ of vessels return within 9 years (Liu and Tsai 2011). Lack of knowledge and inexperience with Australian biosecurity regulations and requirements of vessels that dock in Australian ports likely explains their lower pass rates. The Australian government leverages this risk difference by imposing a reduced intervention strategy for commercial vessels that meet certain lower risk requirements, including a minimum of three visits in a twelve-month period (DAWR, 2017).

Yachts showed statistically lower biosecurity risk than other vessel classes in this study; vessels other than yachts had 13 times greater statistical odds of failure. However, this difference is due to several factors. The biosecurity risk presented by yachts is managed differently than commercial vessels because yachts present a different risk profile for several reasons, including (i) the types of biosecurity risk carried, (ii) the absence of broader regulation, and (iii) different accountability over their operation. Commercial vessels operate under greater regulation and accountability such as compliance with IMO standards, insurance company requirements, formalized shipping schedules, etc. Furthermore, for a given biosecurity threat, yachts present a higher level of risk because of their greater potential for penetration into novel isolated and unmonitored environments such as estuaries and streams. Previous studies deemed recreational boats and yachts to be higher risk, particularly for hull fouling (e.g. Acosta et al. 2010; Floerl et al. 2005). Undeclared vessels were extremely risky but are also rare.

The 12 major north-eastern ports of Australia had the greatest number of arrivals and also higher risk; however the single port with the greatest relative importance was in north-west Australia, Port Hedland, which is unsurprising given it is the largest bulk export port in the world (Pilbara Ports Authority 2016). 
Using the model in this study to predict high risk vessels is a trade-off between the cost of inspections versus the cost of missing a genuine failure. Increasing the sensitivity of the predictions to increase the number of genuine failures detected will increase the rate of false positives. Reasonable predictions could be obtained at higher screening levels, for example the top $30 \%$ of vessels predicted as high risk by the model contained almost $70 \%$ of vessels which were genuine failures, without having to sample more than $70 \%$ of genuine passes.

Some vessels failed biosecurity requirements for relatively minor reasons including documentation errors, which were the most common, but also serious issues that include failure to appropriately manage ballast water, and the detection of non-indigenous organisms. When combined with non-conformities, ballast water and detection of plant and insect materials were the highest ranked reasons for not passing biosecurity procedures. The importance of ballast water for dispersing non indigenous marine organisms is recognised (e.g. Carlton 1996; Seebens et al. 2013) with several billion tons released internationally every year (Endresen et al. 2004). However biofouling may be equally important (Roberts and Tsamenyi 2008) but more difficult to detect from land based assessments, which may explain its lower rates of biosecurity failure in this study. Merchant vessels are by far the largest type of international vessel arrivals but generally are considered to have low incidence of fouling due to maintenance and consistent service (Hopkins and Forrest 2010). This is not always the case and in a recent study $80 \%$ of commercial vessels assessed had evidence for sea-chest fouling and almost half had at least one non-indigenous species present (Frey et al. 2014). Vessel origin and time since last cleaning were important in explaining sea-chest fouling, but vessel size and duration in port were not important to explain species richness or abundance (Frey et al. 2014). Of the 2000 merchant vessels arriving in New Zealand annually, the incidence of non-indigenous and cryptogenic species is approximately four per vessel (Hopkins and Forrest 2010; Inglis et al. 2010). 
Organisms seized or removed from international vessels arriving in Australia were largely invertebrate species groups. The rates of seizures of specific organisms which are of significant biosecurity concern were low relative to the volume of vessels. For example, the Giant African snail was detected 15 times and the Asian gypsy moth 45 times within six years. The eleven species identified that are significant biosecurity pests made up $4.8 \%$ of all organism detections and seizures. This represents 30 vessel arrivals per year with significant invertebrate biosecurity pests present from the more than 15,000 arriving. While this rate of arrival is low, an incursion of any one of these organisms could have significant implications for agriculture, international trade, the economy and environment. For example, the conservative cost estimate of the 2001 Red imported fire ant (S. invicta) incursion, is more than \$AUD 8.9 billion over 30 years excluding environmental costs (Canyon et al. 2002), which makes even a single incursion a significant biosecurity breach. The cost of exotic invertebrates to Australia is estimated to be between \$AUD 5-8 billion per annum, including production losses (Canyon et al. 2002). The number of vessels arriving with species of biosecurity concern is likely to increase, as expanding and changing trade dynamics influence shipping routes, and provide non-indigenous organisms with new and greater opportunities to invade (Carlton 1996; Hulme 2009; Minchin and Gollasch 2003).

The presence of specific species is not necessarily associated with significant biosecurity risk as risk can depend on whether the species is already present, whether they are capable of establishing in the destination port and the likely consequences of establishment (Coutts and Taylor 2004). However, the high species richness and abundance of non-indigenous invaders has led to significant shifts in population, community and ecosystem dynamics (Carlton and Geller 1993; Molnar et al. 2008; Ruiz et al. 1997). Unfortunately, the dataset available for analysis was heavily biased towards terrestrial organisms so it was not possible to measure the incursion rates of marine invaders. 
Our results show that biosecurity risk is not uniform on maritime pathways, so there is considerable scope for biosecurity regulators to impose risk-based intervention, either using the results of an analysis such as documented here, or using an adaptive algorithm such as the Australian government's Vessel Compliance Scheme.

\section{International Context}

Managing biosecurity issues from shipping requires unifying international regulations, vessel technology and ecological conservation (Endresen et al. 2004). There is generally a slow uptake of international regulations which encourage countries to enforce their own local and regional controls relevant to their needs and increasingly based on ship-specific risk assessments (Endresen et al. 2004; Keller et al. 2011). Despite regulations to prevent incursions in the US, there is still a decade on decade increase in invasive species (Ruesink et al. 1995). At lowest forecasts the US alone will see a 3-6\% increase in the establishment of nonindigenous species in two decades, but potentially as high as $24 \%$ (Levine and D'Antonio 2003). The effects of nonindigenous species and costs of control could amount to more than \$US130 billion annually in the US alone (Pimentel et al. 2000). Vessels without a regular shipping route can berth in international ports in almost all biological regions on earth within just a few years (Minchin and Gollasch 2003). However trade and introduction of exotic species is not a linear relationship, i.e. each new ship does not bring a new suite of species, but samples from regions where other ships have already visited (Levine and D'Antonio 2003).

Allowing all nonindigenous species in would be devastating ecologically, but keeping everything out is unrealistic economically and politically (Ruesink et al. 1995). The issue then becomes how to minimise the risk and identify effective management/regulatory actions. Economic considerations affect the transport of nonindigenous species and the investment of 
resources in preventing their incursion, or control once they have arrived (Leung et al. 2002). The level of acceptable risk occurs when the projected damage of a species is less than the cost of its prevention and control. Many countries are moving to more risk based assessments to enable the targeting of high risk vessels (Hewitt and Campbell 2007; Keller et al. 2011). The Australian government uses a risk-sensitive point-based system for lower-risk commercial vessels that satisfy certain conditions (DAWR, 2017). Some studies have used expert judgment (Acosta et al. 2010) which can vary with international regulations, while others have used a small subset of commercial vessels (e.g. Hopkins and Forrest 2010; McCollin and Brown 2014) making broad-scale generalisations difficult. Many lists which counties produce to categorise unwanted exotic organisms are developed by expert opinion or qualitative assessments of their likely impacts and establishment success. These types of risk assessments are difficult to defend/justify scientifically because they cannot make predictions and are rarely subjective (Hayes 2003).

Quantitative prediction techniques to support policy and regulatory decisions can help to provide finite resources more effectively, as well as provide a more objective, viable and financially sustainable assessment of risk (Keller et al. 2011; Leung et al. 2002; Liu and Tsai 2011; Paini and Yemshanov 2012). It is also possible to update these models as new data becomes available and the risk factors change, enabling ongoing predictive modelling. There are thousands of potential species threats and many pre-border pathways on a single vessel despite the apparent focus on ballast water and hull fouling. Species and pathway specific risk assessments are costly and resource heavy. Vector risk assessments in contrast can encompass all pathways and species of concern regardless of threat level, seasonal effects and environmental requirements and do not require large datasets that match environments where species of concern are found with the destination port/country. In the analyses of such data, methods involving many classification trees such as gradient boosting are now considered 
superior to classical methods (Fernández-Delgado et al. 2014) enabling complex and flexible modelling of a large number of potential risk factors.

When implementing a risk-targeted inspection approach, it is important to maintain some level of random sampling so that changes in risk factors can be recognised and the targeting updated when necessary. It is also recommended to continually propose, measure and record other potential risk factors not considered thus far (e.g. flags of convenience; , as well as improve the quality of the agent information so that more inspections can be linked to the agent involved. This paper provides a strong basis for quantitative risk assessments of an entire vector with the availability of such a large database. The results of this analysis can also inform new vessel monitoring systems being developed both within Australia and internationally. 


\section{ACKNOWLEDGEMENTS}

The authors would like to thank the Australian Federal Department of Agriculture and Water Resources (DAWR) for providing the data and motivation for this study. This research was supported by the Centre of Excellence for Biosecurity Risk Analysis, University of Melbourne. 


\section{REFERENCES}

Acosta H, Wu D, Forrest BM (2010) Fuzzy experts on recreational vessels, a risk modelling approach for marine invasions Ecological Modelling 221:850-863

Bax $\mathrm{N}$ et al. (2001) The control of biological invasions in the world's oceans Conservation Biology 15:1234-1246

Bax N, Williamson A, Aguero M, Gonzalez E, Geeves W (2003) Marine invasive alien species: a threat to global biodiversity Marine policy 27:313-323

Brockerhoff EG, Bain J, Kimberley M, Knížek M (2006) Interception frequency of exotic bark and ambrosia beetles (Coleoptera: Scolytinae) and relationship with establishment in New Zealand and worldwide Canadian Journal of Forest Research 36:289-298

Bureau of Infrastructure Transport and Regional Economics (BITRE) (2015a) Australian sea freight 2013-14. Department of Infrastructure and Regional Development, Canberra, ACT, Australia

Bureau of Infrastructure Transport and Regional Economics (BITRE) (2015b) Yearbook 2015: Australian Infrastructure Statistical Report. Department of Infrastructure and Regional Development, Canberra ACT, Australia

Canyon D, Speare R, Naumann I, Winkel K (2002) Environmental and economic costs of invertebrate invasions in Australia. In: Pimentel D (ed) Biological Invasions: Economic and Environmental Cost of Alien Plant, Animal and Microbe Species. CRC Press, London,

Carlton J, Geller J (1993) Ecological roulette: the global transport of nonindigenous marine organisms Science (New York, NY) 261:78-82

Carlton J, Reid DM, van Leeuwen H (1995) The role of shipping in the introduction of nonindigenous aquatic organisms to the coastal waters of the United States (other than the Great Lakes) and an analysis of control options Report to US Coast Guard, Washington DC

Carlton JT (1996) Pattern, process, and prediction in marine invasion ecology Biological conservation 78:97-106

Cope RC, Prowse TAA, Ross JV, Wittmann TA, Cassey P (2015) Temporal modelling of ballast water discharge and ship-mediated invasion risk to Australia Royal Society Open Science 2 doi:10.1098/rsos.150039

Coutts AD, Taylor MD (2004) A preliminary investigation of biosecurity risks associated with biofouling on merchant vessels in New Zealand New Zealand Journal of Marine and Freshwater Research 38:215-229

DAWR (2017) The Vessel Compliance Scheme. http://www.agriculture.gov.au/biosecurity/avm/vessels/mars/vessel-compliance; version 6 January 2017, accessed 29 May 2017.

Endresen $\varnothing$, Behrens HL, Brynestad S, Andersen AB, Skjong R (2004) Challenges in global ballast water management Marine Pollution Bulletin 48:615-623

Fernández-Delgado M, Cernadas E, Barro S, Amorim D (2014) Do we need hundreds of classifiers to solve real world classification problems? The Journal of Machine Learning Research 15:3133-3181

Floerl O, Inglis GJ (2005) Starting the invasion pathway: the interaction between source populations and human transport vectors Biological Invasions 7:589-606

Floerl O, Inglis GJ, Hayden BJ (2005) A risk-based predictive tool to prevent accidental introductions of nonindigenous marine species Environmental Management 35:765778 
Frey MA, Simard N, Robichaud DD, Martin JL, Therriault TW (2014) Fouling around: vessel sea-chests as a vector for the introduction and spread of aquatic invasive species Management of Biological Invasions 5:21-30

Hayes KR (2003) Biosecurity and the role of risk assessment Invasive species: vectors and management strategies Island Press, Washington, DC:382-414

Hewitt CL, Campbell ML (2007) Mechanisms for the prevention of marine bioinvasions for better biosecurity Marine Pollution Bulletin 55:395-401

Hopkins GA, Forrest BM (2010) A preliminary assessment of biofouling and non-indigenous marine species associated with commercial slow-moving vessels arriving in New Zealand Biofouling 26:613-621

Hulme PE (2009) Trade, transport and trouble: managing invasive species pathways in an era of globalization Journal of applied ecology 46:10-18

Inglis $\mathrm{G}$ et al. (2010) The biosecurity risks associated with biofouling on international vessels arriving in New Zealand: summary of the patterns and predictors of fouling. Technical Paper. MAF Biosecurity New Zealand, Wellington, New Zealand

International Maritime Organisation (2012) International Shipping Facts and FiguresInformation Resources on Trade, Safety, Security, and the Environment London: International Maritime Association

Keller RP, Drake JM, Drew MB, Lodge DM (2011) Linking environmental conditions and ship movements to estimate invasive species transport across the global shipping network Diversity and Distributions 17:93-102

Lacoursière-Roussel A, Forrest BM, Guichard F, Piola RF, McKindsey CW (2012) Modeling biofouling from boat and source characteristics: a comparative study between Canada and New Zealand Biological Invasions 14:2301-2314

Leung B, Lodge DM, Finnoff D, Shogren JF, Lewis MA, Lamberti G (2002) An ounce of prevention or a pound of cure: bioeconomic risk analysis of invasive species Proceedings of the Royal Society of London B: Biological Sciences 269:2407-2413

Levine JM, D'Antonio CM (2003) Forecasting biological invasions with increasing international trade Conservation Biology 17:322-326

Liu T-K, Tsai T-K (2011) Vessel traffic patterns in the Port of Kaohsiung and the management implications for preventing the introduction of non-indigenous aquatic species Marine pollution bulletin 62:602-608

McCollin T, Brown L (2014) Native and non native marine biofouling species present on commercial vessels using Scottish dry docks and harbours Management 5:85-96

Miller H, Clarke S, Lane S, Lonie A, Lazaridis D, Petrovski S, Jones O Predicting customer behaviour: The University of Melbourne's KDD Cup report. In: Journal of Machine Learning Research: Workshop and Conference Proceedings, 2009. pp 45-55

Minchin D, Gollasch S (2003) Fouling and ships' hulls: how changing circumstances and spawning events may result in the spread of exotic species Biofouling 19:111-122

Molnar JL, Gamboa RL, Revenga C, Spalding MD (2008) Assessing the global threat of invasive species to marine biodiversity Frontiers in Ecology and the Environment 6:485-492

Paini DR, Yemshanov D (2012) Modelling the arrival of invasive organisms via the international marine shipping network: a Khapra beetle study PLoS One 7:e44589

Pilbara Ports Authority (2016) Port of Port Headland. Port Hedland, WA, Australia

Pimentel D, Lach L, Zuniga R, Morrison D (2000) Environmental and economic costs of nonindigenous species in the United States BioScience 50:53-65

Piola RF, McDonald JI (2012) Marine biosecurity: The importance of awareness, support and cooperation in managing a successful incursion response Marine pollution bulletin 64:1766-1773 
R Core Team (2014) R: A language and environment for statistical computing R Foundation for Statistical Computing, Vienna, Austria URL http://www.R-project.org/

Ricciardi A (2001) Facilitative interactions among aquatic invaders: is an" invasional meltdown" occurring in the Great Lakes? Canadian Journal of Fisheries and Aquatic Sciences 58:2513-2525

Ricciardi A, Neves RJ, Rasmussen JB (1998) Impending extinctions of North American freshwater mussels (Unionoida) following the zebra mussel (Dreissena polymorpha) invasion Journal of Animal Ecology:613-619

Ridgeway Gwcfo (2013) gbm: Generalized Boosted Regression Models R package version 20-8 http://CRANR-projectorg/package $=\mathrm{gbm}$

Roberts J, Tsamenyi M (2008) International legal options for the control of biofouling on international vessels Marine Policy 32:559-569

Ruesink JL, Parker IM, Groom MJ, Kareiva PM (1995) Reducing the risks of nonindigenous species introductions BioScience:465-477

Ruiz GM, Carlton JT, Grosholz ED, Hines AH (1997) Global invasions of marine and estuarine habitats by non-indigenous species: mechanisms, extent, and consequences American Zoologist 37:621-632

Seebens H, Gastner M, Blasius B (2013) The risk of marine bioinvasion caused by global shipping Ecology letters 16:782-790

Thresher RE (1999) Diversity, impacts and options for managing invasive marine species in Australian waters Australian Journal of Environmental Management 6:137-148

Vitousek PM, D’Antonio CM, Loope LL, Westbrooks R (1996) Biological invasions as global environmental change American Scientist 84:468-478

Williams R, Griffiths F, Van der Wal E, Kelly J (1988) Cargo vessel ballast water as a vector for the transport of non-indigenous marine species Estuarine, Coastal and Shelf Science 26:409-420

Wonham MJ, Walton WC, Ruiz GM, Frese AM, Galil BS (2001) Going to the source: role of the invasion pathway in determining potential invaders Marine Ecology Progress Series 215 


\section{TABLES}

Table 1: Variables included in the final modelling analyses after feature selection and the associated non-zero levels. *names omitted.

\begin{tabular}{ll}
\hline Variable name & Levels \\
\hline & Bulk Carrier; Container Vessel; Cruise Vessel; General Cargo; \\
Vessel Type & Irregular Foreign Fishing Vessel; Roll-on/roll-off Cargo, Vessel \\
& Suspected of Irregular Entry; Tanker; Yacht \\
Month of Inspection & $5 ; 7$ \\
Inspection Quarter & Q2; Q3 \\
Year of Inspection & $2007 ; 2008 ; 2009 ; 2010 ; 2011 ; 2012 ; 2013$ \\
Current Docking Port & Adelaide; Botany Bay; Brisbane; Bunbury; Bundaberg; \\
& Christmas Island; Dalrymple Bay; Dampier; Fremantle; \\
& Geraldton; Gladstone; Hay Port; Karumba; Melbourne; \\
& Newcastle; Port Botany; Port Hedland; Port Walcott; Sydney \\
Last Port Visited & Ports with <20 visits; Auckland; Jakarta Java; Noumea; \\
& Surabaya Java \\
Last Country Visited & China; Indonesia; Japan; New Caledonia; New Zealand; \\
Arrival Region & Philippines; Vanuatu; Unknown \\
Name of Vessel & N; NE; SE; SW \\
Agent name & Vessels with <20 visits; Vessels with 20-99 visits \\
Month of Visit & Agent 0001*; Agent 0002*; No match \\
Visit Quarter & 5; 7; 12 \\
Year of Visit & $2 ; 3$ \\
Length of Vessel & $2007 ; 2008 ; 2009 ; 2010 ; 2011 ; 2012 ; 2013$ \\
Vessel Class & Unknown; Yacht (<25 metres) \\
\hline
\end{tabular}


Table 2: Relative variable importance results for analysis of vessel failures for the top 18 factor levels. Odds ratio effects can be accumulated by multiplication.

\begin{tabular}{clrrr}
\hline Rank & Factor and level & & Odds & Rarity \\
& Importance & \multicolumn{1}{c}{ Ratio } & \multicolumn{1}{c}{$(\%)$} \\
\hline 1 & Visit vessel class: Undeclared & 100 & 70.2 & 0.4 \\
2 & Vessel type: Vessel Suspected of Irregular Entry & 30 & 907.5 & 0.2 \\
3 & Current docking port: Port Hedland & 18 & 1.5 & 7.7 \\
4 & Arrival Region: NE & 16 & 1.8 & 29.0 \\
5 & Vessel name: less than 20 visits & 16 & 2.7 & 65.1 \\
6 & Current docking port: Dalrymple Bay & 13 & 3.2 & 3.4 \\
7 & Current docking port: Adelaide & 13 & 3.9 & 0.8 \\
8 & Vessel type: Bulk Carrier & 12 & 1.8 & 54.3 \\
9 & Current docking port: Christmas Island & 11 & 6.3 & 1.3 \\
10 & Year of visit: 2012 & 10 & 1.7 & 13.6 \\
11 & Current docking port: Hay Point & 10 & 3.6 & 2.4 \\
12 & Arrival Region: N & 8 & 2.1 & 12.7 \\
13 & Vessel type: not Yachts & 8 & 12.9 & 94.3 \\
14 & Vessel type: Irregular Foreign Fishing Vessel & 7 & 29.3 & 0.2 \\
15 & Year of inspection: 2013 & 7 & 1.8 & 11.0 \\
16 & Year of inspection: 2012 & 6 & 1.6 & 13.6 \\
17 & Current docking port: Karumba & 6 & 5.1 & 0.3 \\
18 & Year of visit: not 2007 & 5 & 3.2 & 86.3 \\
\hline
\end{tabular}


Table 3: Performance of the prediction model on test data for a variety of screening fractions

\begin{tabular}{ccccc}
\hline Fraction & Sensitivity & Specificity & Odds Ratio & 95\% Confidence Interval \\
\hline $10 \%$ & 0.38 & 0.91 & 6.58 & $(6.16,7.03)$ \\
$20 \%$ & 0.57 & 0.82 & 5.94 & $(5.58,6.32)$ \\
$30 \%$ & 0.69 & 0.72 & 5.76 & $(5.39,6.15)$ \\
$40 \%$ & 0.78 & 0.62 & 5.90 & $(5.48,6.35)$ \\
$50 \%$ & 0.85 & 0.52 & 5.96 & $(5.48,6.50)$ \\
$60 \%$ & 0.90 & 0.41 & 6.57 & $(5.94,7.29)$ \\
$70 \%$ & 0.94 & 0.31 & 7.71 & $(6.77,8.83)$ \\
$80 \%$ & 0.97 & 0.21 & 9.00 & $(7.52,10.86)$ \\
$90 \%$ & 0.99 & 0.10 & 11.34 & $(8.43,15.65)$ \\
\hline
\end{tabular}


Table 4: The rates of failure and non-conformity of international vessels for the different types of biosecurity risk categories between 2012 and 2013

\begin{tabular}{lrrr}
\hline Types of Biosecurity risk material (BRM) & Failure Rate & Non Conformity & \multicolumn{1}{c}{ Total } \\
\hline Plant/Insect & $0.76 \%$ & $1.01 \%$ & $1.77 \%$ \\
Ballast water & $0.63 \%$ & $1.90 \%$ & $2.53 \%$ \\
Living animal & $0.00 \%$ & $0.13 \%$ & $0.13 \%$ \\
Waste & $0.51 \%$ & $0.76 \%$ & $1.26 \%$ \\
Biofouling & $0.13 \%$ & $0.00 \%$ & $0.13 \%$ \\
Declined documentation error & $1.26 \%$ & $0.38 \%$ & $1.64 \%$ \\
Other & $0.13 \%$ & $0.25 \%$ & $0.38 \%$ \\
\hline
\end{tabular}




\section{FIGURES}

Figure 1: The performance of the prediction model on test data, depicted as a ROC curve.

Figure 2: Estimated proportion of seizures or removals of different biosecurity risk organisms from vessel incident data from $1^{\text {st }}$ January 2010-31 $1^{\text {st }}$ December 2015.

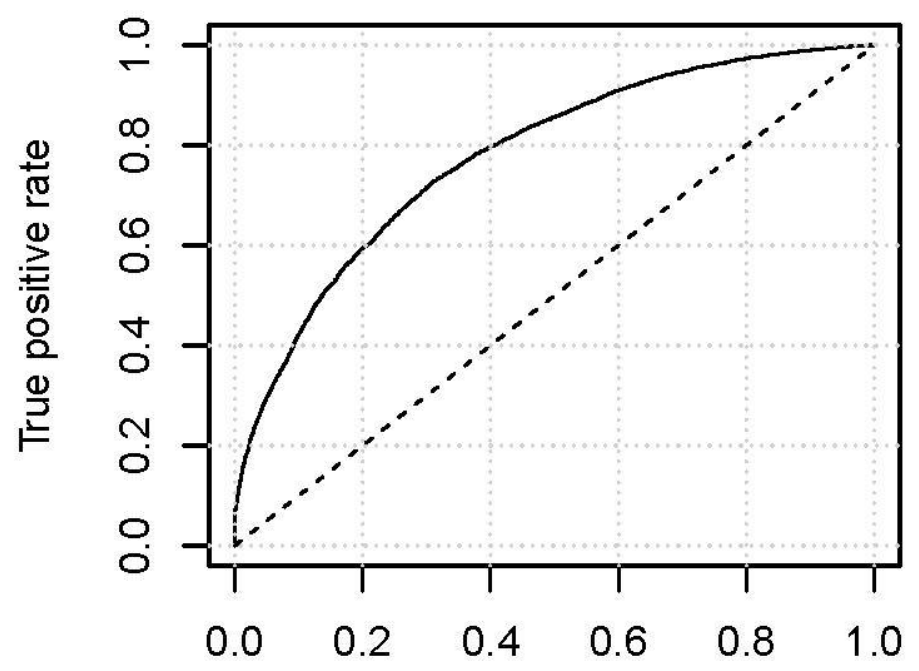

False positive rate

Figure 1: The performance of the prediction model on test data, depicted as a ROC curve. 
a)

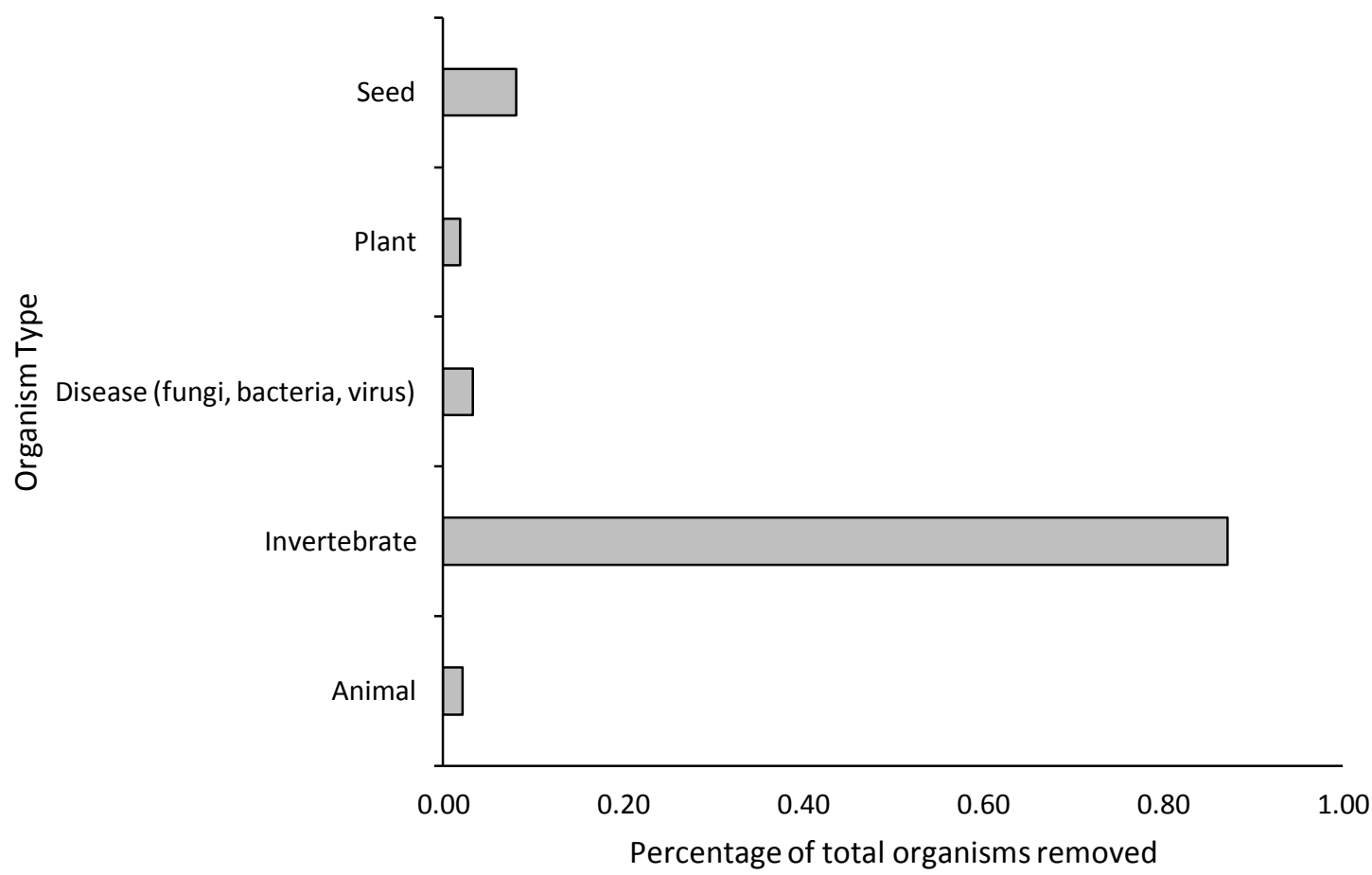

b)

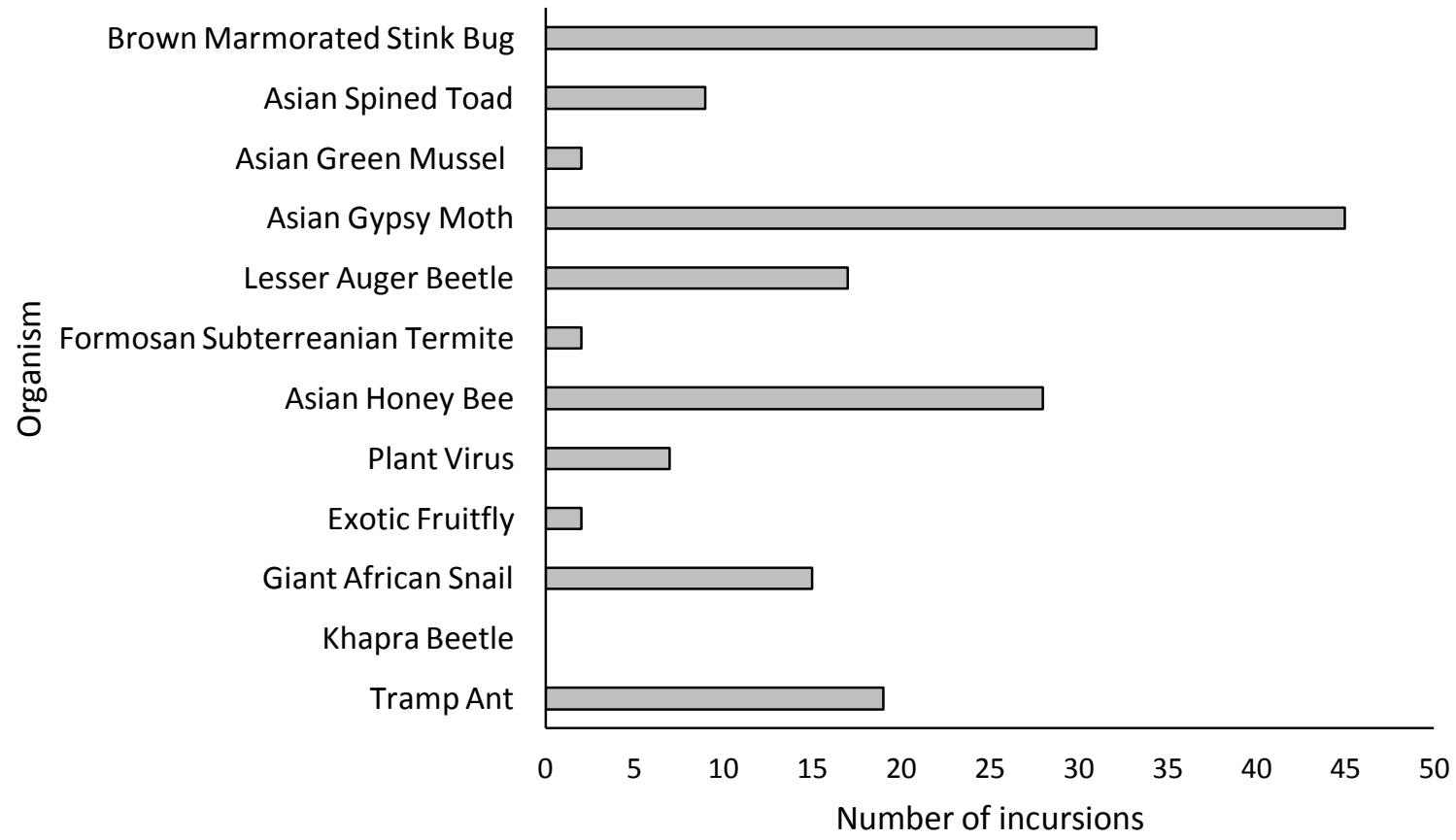

Figure 2: Estimated proportion of seizures or removals of different biosecurity risk organisms from vessel incident data from $1^{\text {st }}$ January 2010-31 ${ }^{\text {st }}$ December 2015. 


\section{University Library}

\section{- M M I N E R VA A gateway to Melbourne's research publications}

Minerva Access is the Institutional Repository of The University of Melbourne

Author/s:

Clarke, S;Hollings, T;Liu, N;Hood, G;Robinson, A

Title:

Biosecurity risk factors presented by international vessels: a statistical analysis

Date:

2017-10-01

Citation:

Clarke, S., Hollings, T., Liu, N., Hood, G. \& Robinson, A. (2017). Biosecurity risk factors presented by international vessels: a statistical analysis. BIOLOGICAL INVASIONS, 19 (10), pp.2837-2850. https://doi.org/10.1007/s10530-017-1486-1.

Persistent Link:

http://hdl.handle.net/11343/283238 